Article title: Exploring Emerging Learning Models in the Advent of the Fourth Industrial Revolution

Authors: Baxolile Mabinya[1], Themba Mgozi[2], Soane Mohapi[3]

Affiliations: College of Education, UNISA, Preller Street, Pretoria, Gauteng, South Africa[1]

Orcid ids: 0000-0002-4013-6215[1], 0000-0003-1577-7667[2], 0000-0001-7362-631X[3]

Contact e-mail: baxolile.mabinya@deviare.africa

License information: This work has been published open access under Creative Commons Attribution License http://creativecommons.org/licenses/by/4.0/, which permits unrestricted use, distribution, and reproduction in any medium, provided the original work is properly cited. Conditions, terms of use and publishing policy can be found at https://www.scienceopen.com/.

Preprint statement: This article is a preprint and has not been peer-reviewed, under consideration and submitted to UnisaRxiv for open peer review.

DOI: $10.25159 /$ UnisaRxiv/000004.v1

Preprint first posted online: 30 April 2021

Keywords: Fourth Industrial Revolution, artificial intelligence, learning models, learning styles 


\section{Exploring Emerging Learning Models in the Advent of the Fourth Industrial Revolution}

Baxolile Mabinya

https://orcid.org/0000-0002-4013-6215

Deviare, South Africa

Baxolile.mabinya@deviare.africa

\section{Soane Mohapi}

https://orcid.org/0000-0001-7362-631X

University of South Africa

\author{
Themba Mgozi \\ https://orcid.org/0000-0003-1577-7667 \\ VirtualX Academy, South Africa
}

\section{Abstract}

The purpose of this paper is to explore emerging Fourth Industrial Revolution themes that have the potential to dramatically alter learning models for the better. The interpretation of learning models includes the relationship between learning theories, learning styles, and the various modes of learning and teaching. Technologies such as artificial intelligence and blockchain empower us to understand our prior ignorance regarding the environment of learning and teaching. A series of documents and reports on the Fourth Industrial Revolution and learning models were analysed in conjunction with the review of recent literature to identify emerging themes that could fundamentally change the way teaching and learning are implemented. Mass personalisation, embedded learning experience, and education as an extension of self are all themes emerging from the possibilities of the Fourth Industrial Revolution and the application of its technologies. Although these themes are at a nascent stage of development, their potential should be understood and nurtured because they can be the source of effective and sustainable developments in the education sector. It is clear from this paper that the impact of the Fourth Industrial Revolution is well beyond the tools and technologies to make what already exists better, and that it rather has an impact on the structure and nature of education itself. The emergence of these themes makes it possible to dramatically change the way we learn and teach. We must be collectively conscious and identify the key aspects of the Fourth Industrial Revolution whose momentum we should use to redress socio-economic challenges in the education environment.

Keywords: Fourth Industrial Revolution, artificial intelligence, learning models, learning styles

\section{Introduction}

With the advent of the Fourth Industrial Revolution (4IR) we now have a symbiotic relationship between human and machine intelligence, creating cyber-physical systems which are driven by technologies such as artificial intelligence (AI), the internet of 
things (IoT), robotics, blockchain, big data and 3D printing (Kayembe and Nel 2019). At the core of this fundamental shift is our ability to leverage data and use technologies to create fundamentally new perspectives and possibilities that will likely have an impact on the way we live. Salmon (2019) describes the 4IR as

a complex notion based on the fusion of cyber and physical systems where machines are interconnected and able to independently communicate and cooperate throughout the manufacturing and production processes.

A more comprehensive definition is offered by the South African Presidential Commission on the Fourth Industrial Revolution (Republic of South Africa 2020) as follows:

The 4th Industrial Revolution is an era where people are using smart, connected and converged Cyber, Physical and Biological systems and smart business models to define and reshape the social, economic and political spheres.

In its report on the future of schools, the World Economic Forum (WEF) (2020) identifies eight key characteristics that underpin education content and learning experiences in the context of the 4IR. Whereas some of these characteristics focus predominantly on the type of skills required for the 4IR, other characteristics hint at the need to fundamentally change the education model itself. Specifically, the report identifies personalisation, inclusion, and problem-based and lifelong learning as key characteristics that must be built into education influenced by the 4IR (WEF 2020). Leading experts such as Salmon (2019) describe this phenomenon as Education 4.0.

The broad purpose of Education 4.0 is to enhance the life of the student in the world by leveraging the symbiotic relationship between human and machine intelligence as well as key enablers such as ubiquitous connectivity (Salmon 2019). The case for Education 4.0 needs to look beyond the technological advancements of the 4IR and delve deeper, through a collaborative process, into the very nature of education so that a new model can emerge (Grinshkun and Osipovskaya 2020).

Although studies of the 4IR and Education 4.0 point to a need to develop new models of learning, too little is known today about the real impact of the 4IR environment. Many of the driving technologies are at nascent stage and have some way to go before having a noticeable and measurable impact, particularly in far reaching sectors such as education. This is because of the productivity paradox, the lag between technological innovation and growth of productivity (Penprase 2018). As a result, the impact of the 4IR still largely focuses on certain aspects such as curricula (Menon and Castrillón 2019) and skills (WEF 2020) where there is enough evidence and documented requirements, and less on emerging aspects that could fundamentally change the very nature of education. 
This paper argues that given the early stages of the 4IR, we must continuously explore and refine emerging learning models as the full extent of the 4IR technologies is revealed with time. There cannot be a perfect or even the right model of learning and delivering education that can be fully designed without the exploration.

\section{Learning Models: Learning Theories, Styles and Methods}

Learning models are underpinned by learning theories which are grouped into three main categories, namely, behaviourism, cognitivism and constructivism. Behaviourism bases learning on external stimuli to and reactions of the learner as a way to create new associations and achieve learning (Stevens-Fulbrook 2020). Repeated actions followed by verbal reinforcement and incentives help to manage behaviour and consequently facilitate learning. The cognitive theory was developed in the early 1900s and focuses on our ability to process information and find new explanations about the world around us (Stevens-Fulbrook 2020).

Constructivism is a learning theory in which the learner plays an active role in constructing their own understanding through building conceptual structures (StevensFulbrook 2020). This is based on tapping into prior knowledge and experiences. Students may engage in problem-based learning and call on their prior experiences and knowledge to solve problems.

Cognitive style and learning style are concepts that are often used interchangeably. Cassidy (2004) defines a cognitive style as an individual's preference for problemsolving, thinking and remembering whereas a learning style is the application of the cognitive style in a learning situation. There are some debates among scholars about the way in which learning styles are applied. Pashler et al. (2009) raise the concern that learning styles are usually applied to individuals as types and thereby confine people into specific categories instead of measuring their proclivity levels across numerous dimensions. Examples of learning styles include active-reflective, sensing and intuitive, visual and verbal, and sequential and global learning (Felder and Soloman 2000). There are various models of learning styles that have been developed over time. For example, David Kolb developed the Learning Styles Inventory with a quadrant model that categorises individuals according to their ability to process and perceive information (Kolb 1985).

Teaching and learning methods can be broadly categorised into face-to-face, online and blended or hybrid methods. Face-to-face teaching is the traditional method of teaching that relies extensively on the physical location and its context, and the instructor or teacher. Although this method has been used for centuries (Salmon 2019), it is still the most dominant method of teaching in schools around the world, particularly in underdeveloped communities in which there are limited or no alternatives. The COVID19 pandemic exposed the over-reliance on this face-to-face method and clearly showed 
the inequalities between those who have access to technology infrastructure and other alternatives and those who do not.

The rise of the online learning and teaching method or e-learning has been accelerated recently. A number of companies operating in the online learning market focus either on products such as content and platforms, or on services and technologies such as mobile and learning management systems and learning types which are synchronous or asynchronous (iMarc 2020). Although the growth in online learning has grown significantly, there has been recognition that some things are better learnt through other methods than online. Moreover, institutions that have thrived for many decades and built their business models on face-to-face methods which require expensive infrastructure are not about to give up their advantage and accept a complete disruption to their existing value. The 4IR, however, demands that we consider new innovations and not simply iteratively improve on existing ones. Xing and Marwala (2017) confirm this assertion when distinguishing between evolutionary and revolutionary innovations.

Blended learning is the use of virtual learning environments through the web to provide a real-time, face-to-face learning experience (Salmon 2019). Blended learning could increase the satisfaction and performance of a student by up to 15 per cent more than pure classroom learning (Oke and Fernandes 2020). Improvements in technology continue to encourage the adoption of blended learning across both basic and higher education.

This paper considers the relationship between learning theories, learning styles and learning or teaching modes to be important. Learning theories form the foundation of the way in which learning is understood. From these theories we have the benefit of vast amounts of research in diverse areas of learning styles. Through these studies, we are able to appreciate the way in which students and learners choose or are directed to specific learning styles based on a variety of factors such as expected outcomes or the learning environment. Learning methods are more concerned with the context in which the learning or teaching takes place. Figure 1 illustrates this papers' interpretation of learning models as the broad relationship between learning theories, styles and methods. This broad perspective is consistent with the interpretation of Kshatriya and Keranen (2017) which defines learning models as follows:

Conceptual frameworks that describe a systematic procedure in organising learning experiences to achieve specific learning objectives and serve as a guide for learning and helps teachers in implementing learning activities. 


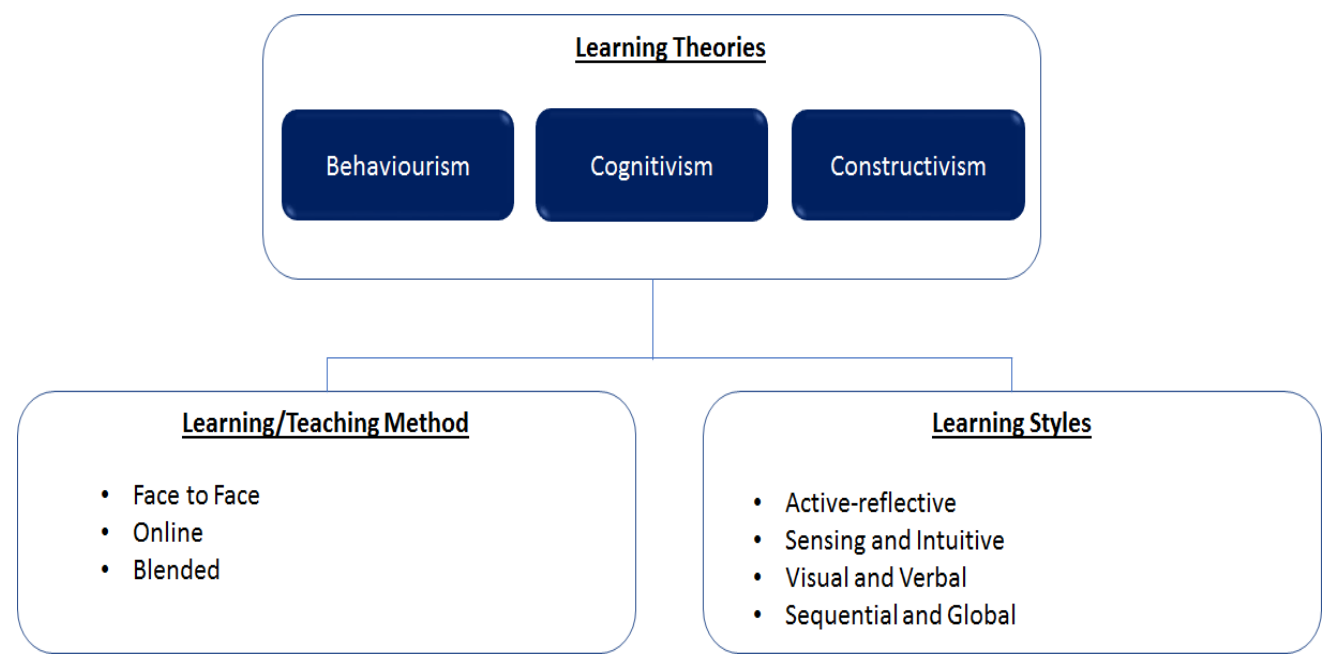

Figure 1: Learning model construct

\section{Key Characteristics of the Fourth Industrial Revolution}

Drawing insights from the book by Rifkin (2011) on the crisis of global economy, the author makes comprehensive arguments - creating an environment for further debate about the establishment of more sustaining systems of the world (Young and Steffen 2009):

The Third Industrial Revolution will have as significant an impact in the twenty-first century as the First Industrial Revolution had in the nineteenth century and the Second Industrial Revolution in the twentieth century.

In transitioning the global economy into a more sustainable future, Penprase (2018) similarly provides further insights, which suggest that the educational plan for the 4IR must be built upon the results of the Third Industrial Revolution. There is a growing consensus among leading researchers suggesting that the 4IR has not started. In fact, various authors further give evidence which emphasises the need for leveraging online courses to strengthen the residential education for undergraduates and to give more flexibility and modularity of courses.

The Third Industrial Revolution, which is generally attributed to computerisation and web-based interconnectivity developed in the 1980s and 1990s, is only now having its rippling effects on society, politics, economics and education. The common narrative is that the First Industrial Revolution used water and steam power to mechanise production. The Second Industrial Revolution used electric power to create mass production. The Third Industrial Revolution used electronics and information technology to automate production. 
As previously stated, the WEF (2016) also agrees that the 4IR is building on the Third Industrial Revolution, the digital revolution that has been occurring since the middle of the last century - characterised by a fusion of technologies that is blurring the lines between the physical, digital, and biological spheres.

There is consensus about what the term "4IR" really means; Penprase (2018) articulates all matters into perspective:

The 4IR often is described as the result of an integration and compounding effects of multiple exponential technologies, such as artificial intelligence (AI), biotechnologies and nanomaterials.

The report by the WEF (2016) points out that the WEF has defined a set of tipping points at which the technologies of the 4IR will become widespread enough to create massive societal change. This includes the proliferation of 4IR technologies to levels where they have such a significant impact on our lives and require shifts in employment and education.

This inexorable shift from simple digitisation to innovation based on combinations of technologies is forcing companies to re-examine the way they do business in changing the way humans create, exchange, and distribute value. As evidenced in the study by Butler-Adam (2018), AI has already arrived in most industries, from self-driving cars and drones to virtual assistants and software that can translate audio into text. The collective viewpoint is that impressive progress has been made in AI in recent years, driven by exponential increases in computing power and by the availability of vast amounts of data, from software used to discover new drugs to algorithms used to predict our cultural interests. Rifkin (2011) further points out that companies and industries have advanced software to connect hundreds of thousands and even millions of small desktop computers and, when connected, the lateral power exceeds, by a magnitude, the computing power of the world's largest centralised supercomputers.

Kayembe and Nel (2019) take the subject even further and refer to innovation and the development of quantum computing which is capable of solving problems in days or even hours as opposed to years. This includes promoting the development of new breakthroughs in science, life-saving medicine, machine-learning methods to diagnose illnesses sooner, materials to make more efficient devices and structures, financial strategies to live well in retirement, and algorithms to quickly direct resources such as ambulances.

\section{Methods and Data Analysis}

This paper reviewed relevant literature and analysed key documents and reports relating to the application of 4IR technologies in the education sector. Figure 2 illustrates the literature and documents which were reviewed and analysed. 


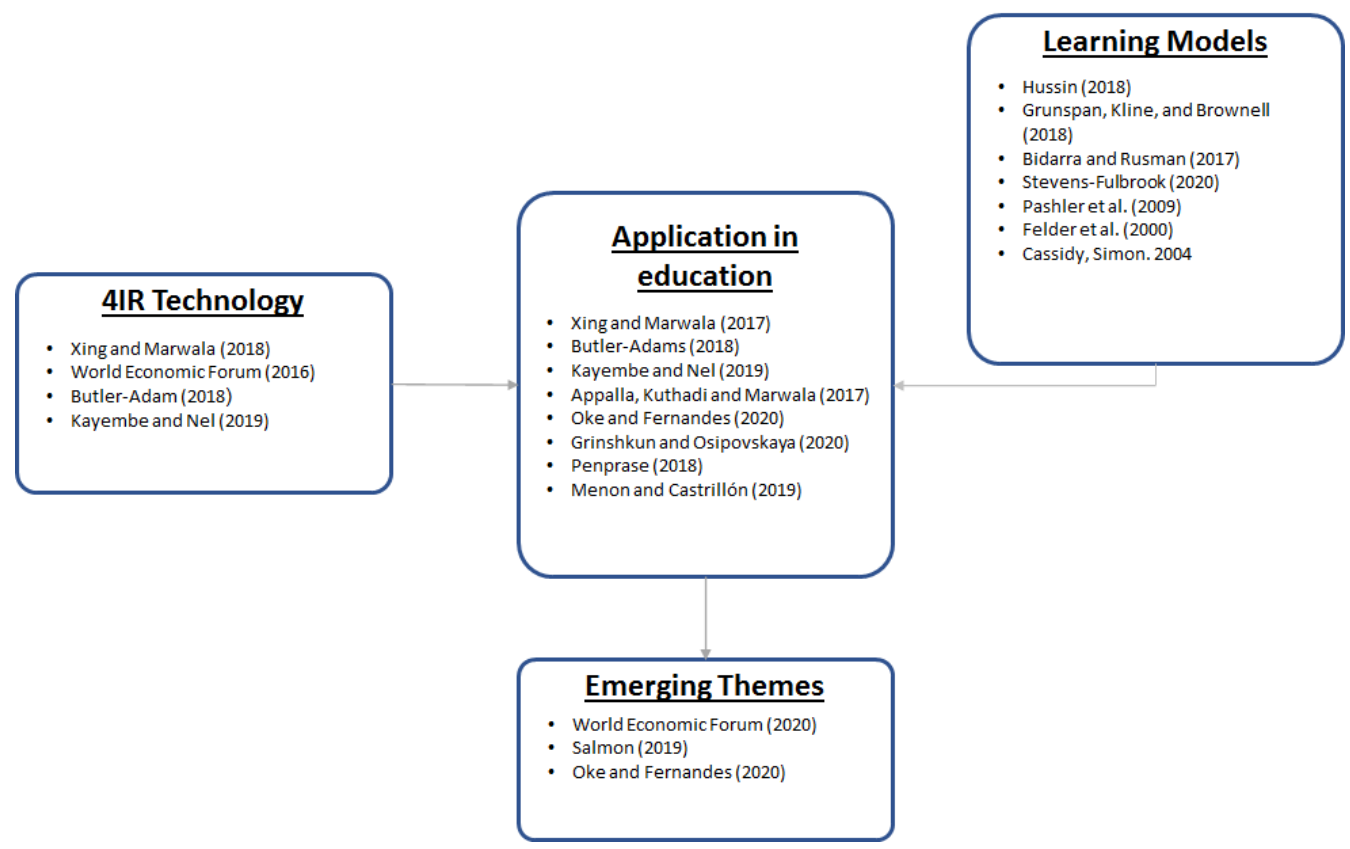

Figure 2: Analysis of literature and documents

The foundation for the impact of the 4IR in education is provided by the WEF (2019) which identifies eight key characteristics in learning and experiences for Education 4.0. The intersection of learning models and the 4IR provides the basis of the analysis in this paper. Oke and Fernandes (2020) provide deductive reasoning and state that there are hundreds of learning theories, but that three categories remain dominant: behaviourism, cognitivism, and constructivism. Further insights to note is that some e-learning designers claim to adhere religiously to one of these categories. Many theories, such as the theory of planned behaviour, the diffusion of innovation, and the technology acceptance model, have therefore been used in empirical studies to understand people's behaviour towards technology adoption. The perceived ease of use and perceived usefulness of technology are the fundamental building blocks for the users' intention to accept technology. The collective arguments suggest that there is a willingness by the education sector to adopt 4IR. This is in recognition that 4IR and its components require less effort and are easy to use, while enhancing the teaching and learning performance.

Oke and Fernandes (2020) make the important observation that technology used in blended learning does not only facilitate interactions between students and instructors, but also augments and transforms the learning and teaching process. This is the context in which Appalla, Kuthadi and Marwala (2017) suggest an efficient educational data mining technique to support e-learning in order to organise learning materials for adaptive and personalised learning experiences. The significance of this observation 
needs further exploration to better understand the way in which 4IR technologies can be leveraged to improve learning models and education.

It is inescapable to observe that the history of education has seen more and more people being granted access to both basic and higher education (Penprase 2018). In order to accommodate such large numbers, a lot of standardisation has had to be done. This has also meant there is less room to personalise learning unless the recipients have the means to pay for such personalisation. All of this is changing fast with the 4IR and new learning models which are developing.

Bidarra and Rusman (2017) note the following regarding emerging learning models:

Gradually, the rupture of traditional assumptions and educational models has propelled cognitive scientists into the exploration of emergent learning formats that might meet the needs of a 'participative learner' by incorporating new kinds of inputs, media consumption and production practices, global resources and accommodate the move into a more learner-centred environment.

Of significant importance in their study is the integration of context (society, knowledge domains, experts, techniques, time and location), technology (devices, content, software, connectivity and network speeds), and pedagogy to propose a framework that can be used to support science education through blended learning. This detailed model appreciates the integrated nature of today's world and encourages a broader perspective of understanding emerging learning models with the change of technology.

\section{Findings and Discussion}

An analysis of the documents and literature revealed some emerging themes that require discussion and further exploration. Mass personalisation, embedded learning, and education as an extension of self are broad themes at the intersection of education development and the 4IR.

\section{Mass Personalisation}

Education, particularly higher education, has experienced global massification in the twentieth century (Xing and Marwala 2017). This trend of providing access to higher education to more than 50 per cent of the global population has meant that learning models have had to be standardised to deal with the large number of students. This standardisation has seen growth and success for education institutions but this massification has also meant the scope to customise learning models to the needs of students is very limited. Dominant logic based on the thinking of the day would influence the nature of learning models.

With the 4IR technologies such as AI, we now have the ability to collect, analyse and make sense of the data that relate to students and the learning environment. A student 
can be much more than a human being with a student number. We can now integrate real data about the lived experience of students in order to tailor, in real time, their learning experiences.

Mass personalisation is about the ability to customise, by using unique data sets, the entire learning experience of students with a view to helping them achieve their objectives. It contradicts the thinking that scale in education, due to massification, means we have to standardise learning models. Furthermore, mass personalisation should not be a concept only for those who can afford it, but rather something that is accessible to all students. The exact same principle could be applied to another important stakeholder in the learning model, the teacher or instructor.

A practical example of mass personalisation is the ability of two students registering for the same course to have very different learning experiences. One student could have a learning path automatically curated to include a language course and suggestions to join a social language group in a nearby community because the data show that, owing to their mother tongue being different from the language of instruction, they need to learn a new language. The second student might be granted access to a relevant sandbox because they have showed a consistent interest in becoming an entrepreneur. The virtual sandbox, integrated to their learning experience, encourages them to create a minimal viable product that can be extended further into a fully-fledged product.

\section{Embedded Learning Experiences}

The 4IR is about the seamless integration between the physical, cyber and biological spheres of life (Kayembe and Nel 2019). Technologies such as virtual and augmented reality combined with AI make it possible to create a new relationship between space, time and person in the context of learning models. Further exploration of this concept of embeddedness creates possibilities where the quality of the learning and teaching is no longer depended on the physical location of the student and teacher. This creates further opportunities for redressing deep inequalities in the global education environment.

Technology in which computers are embedded in human brains to help paralysed people regain independence through the control of computers is at an advanced stage of development (Neuralink.com 2021). There is no reason why similar technologies cannot be applied in improving learning models. For example, using biological data about students to assess their mood and health and thereby adjusting their learning experience is a possibility within our grasp.

\section{Education as an Extension of Self}

It is quite common for those with access to education to "go to school". School, the place of learning, has become an institution outside of the person engaging in the learning process. It is understandable that learning institutions could not accommodate 
the personal and individual desires of every student and tailor their experience to meet this need. All of this could dramatically change in a world in which the learning environment has deep knowledge about who each student is, as a person.

As formal learning becomes less of a limited phase in our lives and more of a constant and necessary feature, it will become increasingly possible to have formal learning as an intrinsic part of who we are. We are no longer going to be confined to learning institutions or dictated to only by external forces in what we learn. More and more, the learning model will be determined by personal identities of those partaking in the learning.

It has been virtually impossible to cater for all the permutations and identities of those that engage in learning through education institutions. In the analysis of this paper, 4IR technologies make it possible to form, analyse and understand the identities of people efficiently. This can be used to weave into the learning experience, aspects that align with a person's identity so that the learning experience can be embedded into the evolution of that identity. This can be the foundation of the concept of lifelong learning, in which people perceive and engage with learning, not as a brief phase of their lives, but as a core part of their lives.

For example, students registering in medicine will have their learning journey aligned to the fundamental reasons why they are interested in the field. People may have vastly different reasons for choosing a specific field of study but in today's world they end up in the same class and if they are lucky, a small part of their identity will be woven into their learning experience.

\section{Conclusion and Implications}

The implications of these emerging themes apply to a wide range of stakeholders. Firstly, the shift towards mass personification brings into sharp focus the role of teaching and instructors. In which way might this role change as a result of 4IR possibilities? Moreover, learning institutions, many of which have a very proud and rich history, need to urgently assess their business models and evaluate their role in future learning models. There is no doubt that governments and policymakers need to find creative ways of giving direction in a world whose uncertainty is ever-increasing at an exponential rate.

Although there are obvious aspects about 4IR technology that might be cause for concern, this should not prevent us from exploring possibilities while finding sustainable ways to deal with the threats. For example, collecting biological data about a person and using it for purposes outside of healthcare is something we have to grapple with legally and ethically. On the flip side, the cost of doing nothing is far greater. It means we forego the practical tools to deal with complex social challenges at scale and essentially abdicate our human responsibility to future generations. 
Owing to the nascent nature of the 4IR and its implication, there is not enough knowledge to completely grasp, with clarity, the type of impact this will have on the education sector. Consequently, we must attempt to pursue a more collaborative process of discovery between those who conduct research (academics), those who implement emerging ideas in reality (entrepreneurs), those who create an enabling and sustainable environment for education to thrive (governments and policymakers), and those whose aspirations need to find expression through education (learners and scholars). We cannot afford to wait for the ideas to mature in isolation of the reality nor can we divorce theory from practice in the context of the 4IR. We must collectively adopt 4IR technologies and adapt their application to redress socio-economic challenges.

\section{References}

Appalla, Padmaja, Venu Madhav Kuthadi, and Tshilidzi Marwala. 2017. “An Efficient Educational Data Mining Approach to Support E-Learning." Wireless Networks 23 (4): 1011-24. https://doi.org/10.1007/s11276-015-1173-z.

Bidarra, José, and Ellen Rusman. 2017. "Towards a Pedagogical Model for Science Education: Bridging Educational Contexts through a Blended Learning Approach.” Journal of Open, Distance and e-Learning 6-20. https://doi.org/10.1080/02680513.2016.1265442.

Butler-Adam, John. 2018. "The Fourth Industrial Revolution and Education." South African Journal of Science 114 (5/6). https://doi.org/10.17159/sajs.2018/a0271.

Cassidy, Simon. 2004. "Learning Styles: An Overview of Theories, Models, and Measures." Educational Psychology 24 (4): 419-444. https://doi.org/10.1080/0144341042000228834.

Felder, Richard, and Barbara Soloman. 2000. Learning Styles and Strategies. Raleigh.

Grinshkun, Vadim, and Elizaveta Osipovskaya. 2020. "Teaching in the Fourth Industrial Revolution: Transition to Education 4.0.” Paper presented at the 4th International Conference on Informatization of Education and E-learning Methodology: Digital Technologies in Education, 6-9 October, Krasnoyarsk, Russia.

Grunspan, Daniel, Michelle Ann Kline, and Sara Brownell. 2018. "The Lecture Machine: A Cultural Evolutionary Model of Pedagogy in Higher Education.” CBE_Life Sciences Education 17 (3). https://doi.org/10.1187/cbe.17-12-0287.

Hussin, Anealka Aziz. 2018. "Education 4.0 Made Simple: Ideas For Teaching." International Journal of Education and Literacy Studies 92-98.

https://doi.org/10.7575/aiac.ijels.v.6n.3p.92.

iMarc. 2020. Africa E-Learning Market: Industry Trends, Share, Size, Growth, Opportunity and Forecast 2020-2025. Noida: iMarc.

Kayembe, Christian, and Danielle Nel. 2019. "Challenges and Opportunities for Education in the Fourth Industrial Revolution." African Journal of Public Affairs 79-94. 
Kolb, David A. 1985. "Learning Styles Inventory." The Power of the $2 x 2.267$.

Kshatriya, Sunitha, and Krista Keranen. 2017. "Building a Case of Diverse Knowledge

Transfer in Higher Education between Finland and Dubai to Facilitate Sustainable 21st Century Learning and Better Engagement of Emirati Students." Al Dar Research Journal For Sustainability 1-13.

Menon, Kirti, and Gloria Castrillón. 2019. "Reimagining Curricula for the Fourth Industrial Revolution.” Independent Journal of Teaching and Learning 14 (2): 6-19.

Neuralink.com. 2021. Engineering with the Brain. April. Accessed 30 April 2021. https://neuralink.com/applications/.

Oke, Adekunle, and Fatima Fernandes. 2020. "Innovations in Teaching and Learning:

Exploring the Perceptions of the Education Sector on the 4th Industrial Revolution (4IR)." Journal of Open Innovation: Technology, Market, and Complexity 6 (2). https://doi.org/10.3390/joitmc6020031.

Pashler, Harold, Mark McDaniel, Doug Rohrer, and Robert Bjork. 2009. "Learning Styles: Concepts and Evidence." Psychological Science in the Public Interest 9 (3): 105-19. https://doi.org/10.1111/j.1539-6053.2009.01038.x.

Penprase, Bryan Edward. 2018. "The Fourth Industrial Revolution and Higher Education.” In Higher Education in the Era of the Fourth Industrial Revolution, edited by N. W. Gleason, 207-229. Singapore: Palgrave Macmillan. https://doi.org/10.1007/978-981-13-0194-0_9.

Rifkin, Jeremy. 2011. The Third Industrial Revolution: How Lateral Power is Transforming Energy, the Economy, and the World. Hampshire: Palgrave Macmillan.

Salmon, Gilly. 2019. "May the Fourth be with You: Creating Education 4.0." Journal of Learning for Development 95-115.

Stevens-Fulbrook, Paul. 2020. An Introduction to Learning Theories. TeacherOfSci.

Republic of South Africa. 2020. Report of Presidential Commission on the 4th Industrial Revolution. Pretoria: Department of Communications and Digital Technologies.

WEF (World Economic Forum). 2016. World Economic Forum Annual Meeting 2016: Mastering the Fourth Industrial Revolution. Annual Meeting Report. Geneva: World Economic Forum.

WEF (World Economic Forum). 2020. Schools of the Future: Defining New Models of Education for the Fourth Industrial Revolution. Contribution to Project. Geneva: World Economic Forum.

Xing, Bo, and Tshilidzi Marwala. 2017. "Implications of the Fourth Industrial Age on Higher Education.” SSRN Electronic Journal. 
Xing, Bo, and Tshilidzi Marwala. 2018. "The Synergy of Blockchain and Artificial Intelligence.” SSRN Electronic Journal. https://doi.org/10.2139/ssrn.3225357.

Young, O. R., and W. Steffen. 2009. "The Earth System: Sustaining Planetary Life-Support Systems." In Principles of Ecosystem Stewardship, edited by C. Folke, G. Kofinas and F. Chapin, 295-315. New York: Springer. https://doi.org/10.1007/978-0-387-73033-2_14. 